\title{
Dossiê
}

Ensino e Pesquisa em História Antiga e História Medieval no Brasil

\section{GÊNERO E HISTÓRIA MEDIEVAL EM TEMPOS DE CRISE: ENTREVISTA COM O MEDIEVALISTA MARCELO PEREIRA LIMA*}

Marcelo Pereira Lima é doutor em História pela Programa de Pós-graduação em História da Universidade Federal Fluminense (UFF) e Pós-doutor pela Universidade de Salamanca (2015), com bolsa concedida pela Coordenação de Aperfeiçoamento de Pessoal de Nível Superior (CAPES). Na atualidade, é Professor Associado I do Departamento de História e do Programa de Pós-graduação em História da Universidade Federal da Bahia (UFBA), onde desenvolve pesquisas com seus orientandos e orientandas sobre Estudos de Gênero, Medievo nas mídias, História Comparada e Transmissão Textual em períodos não-modernos. Ademais, atua ativamente em diversos grupos e laboratórios de pesquisa do Brasil vinculados à História Medieval, Relações de Poder e Gênero como o Vivarium Núcleo Nordeste (UFAL), Translatio Studii (UFF), o Cultura Material, Antiguidade e Cotidiano (CMAC/UFBA) e PEM-UFRJ. É fundador e coordenador do Laboratório de Estudos sobre a Transmissão e História Textual na Antiguidade e Medievo (LETHAM-UFBA) juntamente com o professor doutor Marco Aurélio Oliveira da Silva.

Ele é um dos pesquisadores que tem contribuído com o processo de ampliação dos estudos medievais na UFBA, na Bahia e no Nordeste. Da sua produção acadêmica destaca-se a tradução e ampliação de fontes no cenário brasileiro, com a obra Documentação diplomática da diocese de Sigüenza entre 1124 e 1151), organizada juntamente com Bruno Gonçalves Álvaro (LIMA; ÁLVARO, 2019), e Políticas em História: instituições, poderes e historiografia, coletânea organizada com a professora Ana Paula Médici (LIMA; MÉDICI, 2019). Entre os seus artigos mais recentes, podemos citar "Poderes, corpos e performances de gênero: feminilidades e masculinidades no Tratado en defensa de virtuosas mujeres de Diego de Valera", publicado na revista Anos 90 (LIMA, 2020), e "Gênero, Ensino de História e Medievalidades: (des)conexões com o passado", publicado na Signum, revista da Associação Brasileira de Estudos Medievais (Abrem) (LIMA, 2019). Por fim, é editor gerente e membro do Conselho Editorial da revista

\footnotetext{
* Entrevista realizada pelos(a) mestrandos(a) do Laboratório de Estudos sobre a Transmissão e História Textual na Antiguidade e Medievo (LETHAM-UFBA) e do Programa de Pós-Graduação em História (PPGH-UFBA) Alan Rebouças Pereira, Beatriz Galrão Abrantes, Lucas Vieira de Melo Santos, Magide Jarallah Dracoulakis Nunes e Thiago Souza de Jesus.
} 
Veredas da História (UFRRJ) e membro do Conselho Editorial de Levar Anclas Ediciones, da Asociación Pares Académicos em RedPAR, desde 21 de janeiro de 2017.

Nesta entrevista, o professor Marcelo Lima responde a questões sobre o campo da História, da História Medieval e do Ensino de História, sobretudo as relacionadas com as contribuições e experiências do LETHAM para a produção do conhecimento crítico.

LETHAM: Para iniciarmos nossa entrevista, gostariamos que comentasse um pouco sua trajetória acadêmica. Quando o Medievo se tornou um perído importante para as suas atividades universitárias? E como tem sido o desenvolvimento dos campos da pesquisa, ensino e extensão na UFBA?

Marcelo Pereira Lima (MPL): Em primeiro lugar, agradeço o convite feito pelos alunos e aluna do LETHAM para inaugurar a série de entrevistas que serão realizadas pelo laboratório daqui para frente. Considero importante a iniciativa, já que ela também constitui um esforço de construção de memória acadêmica e de síntese da atuação desse grupo no âmbito do Departamento de História e do Programa de Pós-Graduação em História da UFBA.

Sobre a pergunta, fiz a graduação em História (1993-1997) no Departamento de História da UFRJ, hoje, Instituto de História, e o mestrado em História Social (2000-2001) pelo PPGHIS-UFRJ, dois cursos localizados no Instituto de Filosofia e Ciências Sociais (IFCS). Ambos foram realizados também no âmbito do Programa de Estudos Medievais da UFRJ, coordenado pelas professoras Andreia Lopes Frazão da Silva e Leila Rodrigues da Silva. Fui orientado pela Andreia Frazão na graduação e no mestrado. Na graduação trabalhei com a História Cultural do Direito Canônico, com o tema do celibato em atas conciliares ou decretos papais. Depois dediquei-me ao estudo das representações dos casamentos medievais em cartas pontifícias, as chamadas decretais, no papado de Inocêncio III (1198-1216). Antes disso, a História Medieval não era uma preocupação exclusiva nos meus estudos acadêmicos. Mesclava uma pesquisa no PIBIC (1995-1996) sobre as relações entre o liberalismo e os militares na imprensa de 1830, discutindo os aspectos ideológicos da formação do Estado no século XIX, com uma investigação inicial (1994-1995) sobre o tema da reforma papal, celibato e casamento na Idade Média. O ambiente do PEM serviu de estímulo para que ficasse claro que os estudos medievais eram o que desejava fazer nas atividades de ensino, pesquisa e extensão. A despeito dos limites institucionais que afetavam as Ciências Humanas e a História como um todo, o programa era o espaço de sociabilidades intelectuais que permitia obter material de leitura (documentos, livros, artigos etc.), quase sempre fotocopiados, retirados das bibliotecas ou generosamente cedidos dos arquivos pessoais das professoras Andreia Frazão e Leila Rodrigues. Era um lugar de encontros, ciclos, palestras, congressos, cursos, minicursos, bancas, reuniões de laboratórios, disciplinas optativas e obrigatórias, tirocínios... Foi no âmbito do PEM que encontrei espaço para aprender que as dificuldades de pesquisa, em vez de limitar, conter e desestimular, poderiam ser potencializadoras para superar e contornar os problemas com o trabalho colaborativo. Fiz o doutorado na UFF e fui orientado pelo professor Mário Jorge da Motta Bastos e pesquisei o tema das transgressões sexuais, sobretudo o adultério no mundo ibérico castelhano-leonês a partir da perspectiva 
de gênero. Encontrei na UFF e no Translatio Studii - Núcleo Dimensões do Medievo (História, Língua e Filosofia) o mesmo ambiente colaborativo para o desenvolvimento de atividades de pesquisa, ensino e extensão que carrego comigo ainda hoje. Mas a preocupação com o gênero, como perspectiva e objeto de investigação, iniciou-se bem antes do doutorado e vejo como marco importante de inflexão um artigo que escrevi junto com a professora Valéria Fernandes da Silva, em 2002, intitulado "O poder da fala e a imposição do silêncio: exercício da religiosidade laica e restrições de gênero no século XIII" (LIMA; SILVA, 2002, p. 153-161). Fazendo uma retrospectiva macro-histórica da minha trajetória, considero que me desloquei das investigações da História Cultural dos discursos e das representações para os Estudos Feministas e os Estudos de Gênero, especialmente preocupando-me com questões ligadas a temas epistemológicos, a História da Historiografia e a aplicação da categoria gênero para períodos nãomodernos. As interconexões entre a História Políticas das Instituições (Direito, Igreja, Monarquia) e os Estudos de Gênero são o que têm mobilizado minhas preocupações. Hoje, embora não deixe de lado a História da Igreja e do Papado nos séculos XII e XIII, e da Monarquia de Leão e Castela no século XIII, tenho trabalhado com uma documentação chamada ejecutorias em Castela dos séculos XIII ao XVI a partir da perspectiva de gênero.

Inspirando-me nas experiencias prévias da UFRJ e da UFF, e em parceria com o professor de filosofia medieval, Marco Aurélio, do Departamento de Filosofia e do Programa de Pós-Graduação em Filosofia daqui da FFCH-UFBA, coordeno o LETHAM, que é a sigla do Laboratório de Estudos sobre a Transmissão e História Textual na Antiguidade e no Medievo. Essa instituição substituiu a experiência do Vivarium-UFBA, que havia sido criado em 2014, com a função de agregar pesquisadores e estimular atividades da área, repetindo experiências similares do Vivarium-UFMT, Vivarium-UFS (que deu lugar ao Dominium-UFS) e Vivarium-UFAL. A ideia desse laboratório é criar uma rede local, nacional e internacional de divulgação de conhecimentos, de integração e colaboração entre quem se interessa por essas temporalidades. É um grupo interdisciplinar de pesquisa, associado a essa Faculdade que mencionei, e é um grupo que foi certificado e registrado no Diretório do CNPq desde outubro de 2016. Ele tem como principal iniciativa proporcionar a consolidação das pesquisas acadêmicas acerca dos estudos sobre a Antiguidade e o Medievo no estado da Bahia, obviamente sem deixar de articular-se com as investigações nacionais e internacionais. Esse grupo é constituído por profissionais das áreas de História, das Letras e da Filosofia e procura contribuir de alguma maneira para a formação qualificada de profissionais que sejam capazes de atuar no âmbito regional, assim como fortalecer as áreas de ensino, pesquisa e extensão na UFBA. O Laboratório desdobra-se basicamente em diversas linhas de pesquisa, abarcando profissionais e estudantes em diferentes fases de formação, seja na graduação, pós-graduação e egressos e egressas. Entre as linhas de pesquisa, podemos citar: Paleografia, codicologia e edótica Latina; Produção, transmissão e edição de manuscritos latinos e vernáculos; Ensino de História, Filosofia, Línguas e Literaturas sobre a Antiguidade e o Medievo; Estudos de Gênero e Investigações Interdisciplinares sobre a Antiguidade e o Medievo; Estudos de gênero, sexualidades transgressoras e corpo: aspectos teóricos, metodológicos e epistemológicos; Medievalísticas e medievalidades em 
suportes multimidiáticos; Estudos iconográficos e vida material na Antiguidade e no Medievo; Relação entre conhecimento e fé na Escolástica Latina; Desejo e Ética na Tradição Aristotélica; Relações de poder, cultura e instituições na Antiguidade e Medievo; História Comparada das Religiões, Poder, Cultura e Instituições; Poder e Cultura nas regiões ibero-mediterrânicas e americanas.

Nesse espaço institucional de sociabilidades e de colaborações acadêmicas, temos nos empenhado para superar os preconceitos e estereótipos de que os Estudos Medievais não deveriam inflar as preocupações acadêmicas ou desperdiçar recursos públicos com épocas remotas, já que o Brasil não teve um Idade Média geográfica. O LETHAM não é a primeira experiência no campo dos Estudos Medievais no Departamento de História. Já existia na grade curricular duas disciplinas dedicadas ao período (História Medieval I e II), algo raro no contexto geral de desenvolvimento desses estudos fora do eixo Sudeste-Sul, embora contassem com uma carga horária de 35h. Elas foram ministradas por docentes não especialistas na área, tais como o professor Waldir Freitas Oliveira, que atuou também nas áreas do Direito, Geografia, História e Economia, ou Cândido da Costa e Silva, formado em Filosofia, Teologia, Ciências Sociais e História Social. O professor Cândido Silva também dava aulas de disciplinas afins como a História das Religiões e a História da Igreja Medieval. Posteriormente, com o primeiro concurso voltado propriamente para História Medieval, em 1999, a professora pesquisadora Edilece Souza Couto assume a cadeira em 2000, que passa a mesclar atividades de ensino, pesquisa e extensão sobre a História das Religiões, História das Religiosidades e História Medieval e, especialmente, sobre temas ligados aos Cristianismo (Catolicismo e Protestantismo), a associações leigas católicas, devoções e festas. Em 2001, com a reforma curricular, as duas disciplinas passaram a ter 68h. Há quase uma década, as disciplinas de História Medieval I e II são alternadamente ministradas pela professora Edilece Couto e, por mim, desde minha entrada na UFBA, em 2011. A partir daí, tenho ofertado disciplinas na graduação e pós-graduação, como "História Social", "Estudos de Gênero: limites e possibilidades dos estudos historiográficos" e "Gênero, poder e instituições na península Ibérica Medieval". Em maior ou menor grau, em todas as disciplinas ministradas, tenho feito um esforço de equilibrar ao menos três dimensões do ofício do(a) historiador(a): a) a análise teórico-metodológica; b) a discussão contextualizada de documentos; c) e, por fim, a problematização da historiografia. O meu desafio tem sido incluir o gênero como perspectiva e fenômeno histórico para entender esse tripé.

LETHAM: Professor, você é especialista em Idade Média, um periodo que tem cerca de mil anos e que é conhecido por muitos como "Idade das Trevas". Poderia nos fažer uma caracterização dessa Idade Média e de onde surgiu essa associação com as trevas?

MPL: A resposta é bastante conhecida nos meios universitários em que há pelo menos uma ou duas disciplinas obrigatórias sobre o Medievo. Há autores e autoras brasileiros(as) ou estrangeiro(as) que já responderam a essa questão com mais profusão e profundidade do que o farei aqui (BASCHET, 2006; FRANCO JUNIOR, 2001; SILVA, 2019, p. 7-13). Porém gostaria de pontuar alguns aspectos importantes. Aparentemente é um tema batido, mas creio que revisitá-lo todo o semestre nos faz pensar 
sobre os caminhos do ofício historiográfico. Como falei antes, tenho me empenhado em equilibrar as atividades de ensino, pesquisa e extensão no tripé das análises documentais, historiográficas e teóricometodológicas. Dependendo do público-alvo, o tema dos estereótipos sobre a Idade Média é uma preocupação constante, impelindo-nos a discutir as raízes das idealizações desde o século XV até o XXI. É importante percorrer as visões renascentistas, iluministas e românticas, até chegar às concepções de Medievo adotados por diversas correntes historiográficas contemporâneas. Mapear as idealizações negativas e positivas sobre esse período convencional de mil anos é uma tarefa relativamente realizada do ponto de vista histórico, especialmente quando levamos em conta os séculos XV, XVI, XVII, XVIII e XIX, mas as representações extemporâneas sobre o medievo ainda não se tornaram um tema autônomo de pesquisa na graduação e pós-graduação ao menos no campo da História.

Sem dúvida, Jérôme Baschet tem razão ao dizer que a Idade Média foi "balançada de um extremo a outro", sendo um "sombrio contraponto dos partidários da modernidade" ou um "ingênuo refúgio daqueles a quem o presente moderno horroriza" (BASCHET, 2006, p. 24). Ou seja, entre os sarcarmos modernistas e as idealizações românticas, a Idade Média é concebida como uma continuidade perdida e prolongável ou uma inversão do moderno e contemporâneo a ser criticada e esquecida (BASCHET, 2006, p. 24). Por um lado, ela é vista como período dominado por uma Igreja monolítica, poderosa e tentacular, que tudo abarcaria e controlaria, uma fase movida por arbitrariedades de homens aristocratas (senhores feudais, condes, duques, reis, imperadores), que submetem, sem resistências, o "povo", mas, igualmente, é abordada como um tempo inflado de superstições, ignorâncias e irracionalidades religiosas. Por outro lado, o Medievo seria um passado inspirador e prolongável no presente, uma época de heroísmo, beleza, fé, tradição, ordem, hierarquia, nobreza caval(h)eiresca e cortesia: aqui, ali ou lá estariam as origens das nações e dos Estados Modernos.

Se a descontinuidade absoluta é uma marca ideológica da primeira tendência, o continuísmo inveterado parece adentrar a segunda, porém ambos escondem a mescla entre o eurocentrismo e o androcentrismo historiográficos. Com isso quero dizer que me parece que o eurocentrismo setentrional, com destaque para a França e Inglaterra, exclui e hierarquiza outros espaço-tempos, como os outros períodos altomedievais e demais regiões euroafroasiáticas (MACEDO, 2017, p. 11-25), reduzindo o potencial de uma história não exclusivamente europeia para análise de períodos não-modernos. ${ }^{1}$ Mas, ao lado das perspectivas eurocêntricas sobre a própria Europa, há outro aspecto que ainda é pouco

\footnotetext{
${ }^{1} \mathrm{Na}$ contramão dessa tendência, podemos citar as várias palestras organizadas pelo LEOM (Laboratório de Estudos de Outros Medievos). No evento "Para além do ocidente Cristão: Outras Idades Médias?", realizado na UFPE, sob a coordenação do pelo professor doutor Bruno Uchoa, a palestra de abertura, intitulada "Adelardo de Bath (1080-1152) e a busca pela terra estrangeira", foi ministrada pelo professor Carlile Lanzieri Júnior, da UFMT-Vivarium (Disponível em: https://www.youtube.com/watch?v=3U40_RKx0pY. Acessado em: 29 ago. 2020). Ouras atividades realizadas no decorrere do evento foram: a palestra "O Kniaz e/contra a Tsrky: Tensões entre o poder laico e a igreja na Rus Kievana (séculos XI e XII)", ministrada pelo professor doutorando Leandro César Santana Neves, do PPGHIS-UFRJ (Disponível em: https://www.youtube.com/watch?v=zScI_BkVvEQ. Acessado em: 29 ago. 2020); a palestra "A quem pertence Al-Andalus? Reflexões sobre os discursos árabes e europeus", ministrada pela professora Celia Daniele Moreira de Souza (Disponível em: https://www.youtube.com/watch?v=eg4ir1Qb4Sk. Acessado em: 29 ago. 2020); a palestra "A Águia de Pedra e o Rinoceronte de Ouro. História, Cultura e Arqueologia nas sociedades do sudeste africano (séculos VI-XVI)", ministrada pelo prof. Dr. Otavio Luiz Vieira Pinto (Disponível em: https://www.youtube.com/watch?v=MjgKUzpz-CY. Acessado em 29 ago. 2020).
} 
estudado: o androcentrismo historiográfico. Apesar do desenvolvimento das pesquisas nos campos da História das Mulheres Medievais, dos Estudos de Gênero, da História das Masculinidades e dos Estudos Queers para se entender o medievo, ainda há um pressuposto de um masculino universal marcando as concepções de sujeito na Idade Média. Isso fica evidente na produção de dicionários temáticos, manuais didáticos ou universitários. Salvo exceções inspiradoras (COSTA; COSTA, 2019; RIVERA GARRETAS, 2005; SILVA, 2004, p. 87-107), o questionamento sobre os estereótipos renascentistas, iluministas e românticos precisam receber uma dose de renovação em pesquisas sobre como e por que as noções de tempo e espaço medievais foram marcadas pelo gênero e outras dimensões sociais e históricas. As "trevas" ou as "luzes" medievais têm um gênero? Trata-se de um horizonte que precisa ser vislumbrado nas investigações acadêmicas.

LETHAM: Muitos jogos, filmes, quadrinhos se utilizam da Idade Média como pano de fundo. E geralmente é uma Idade Média baseada nesses estereótipos mencionados. Como enxerga isso? De que forma isso pode ser utilizado para realização de pesquisas acerca da Idade Média?

MPL: Tenho trabalhado com a noção de medievalidades que foi definida e sistematizada pelo medievalista José Rivair Macedo para estudar o cinema, diferenciando-as das reminiscências medievais. Para esse autor, enquanto estas remeteriam a uma espécie de continuidade do que teria sido propriamente medieval, ou melhor, "algo da realidade histórica da Europa medieval", subsistindo como uma residualidade para além dos séculos $\mathrm{V}$ e XV, aquelas remeteriam a referências fugidias, imprecisas e estereotipadas, mas também a determinados índices de historicidade manifestos em atividades lúdicas, obras artísticas ou técnicas de recriação histórica típicas da indústria cultural. (MACEDO, 2009, p. 1617). Tenho extrapolado essa noção de medievalidades, procurando identificar e analisar as relações de convergência e divergência com o medievalismo historiográfico, especialmente as presentes na cibercultura e nos discursos e suportes multimidiáticos, como filmes, séries de TV, vídeos, textos literários (romances, poesias, cordéis), iconografias, imagens, jogos eletrônicos, RPGs, brinquedos, roupas, feiras comerciais, performances teatrais, músicas, paródias, capas de discos, DVDs, blogs, gifs, memes, hashtags, entre outros. Inclusive, esse foi o tema de um artigo publicado na Signum, de 2019, intitulado "Gênero, ensino de História e Medievalidades: (des)conexões com o passado", cujos objetivos eram situar os estudos das medievalidades e exemplificá-los numa análise do longa-metragem $A$ Bela Adormecida, relacionando-o com seu contextos técnico, estético e histórico, e com os precedentes literários dos contos de fadas elaborados por Giambattista Basile, Charles Perrault e os Irmãos Grimm. O outro exemplo é a palestra com um tema semelhante que ministrei para o Translatio Studii, no dia 28 de agosto de 2020, intitulada “Gênero(s), Ensino de História e Medievalidade(s): notas sobre os usos do passado". ${ }^{2} \mathrm{Na}$ ocasião, dividi a exposição em duas sessões. A primeira dediquei-me à uma espécie de

\footnotetext{
2 Palestra intitulada "Gênero(s), Ensino de História e Medievalidade(s): notas sobre os usos do passado" (ver entre 1 h00 à $1 \mathrm{~h} 31 \mathrm{~m}$ ), ministrada pelo professor Marcelo Pereira Lima (LETHAM-UFBA/PPGH-UFBA). Translatio Studii. Disponível em: https://www.youtube.com/watch?v=YmRNQYHYx9Q. Acessado em: 29 ago. 2020.
} 
flash back para contextualizar o tema no âmbito da minha experiencia como professor e pesquisador, ou melhor, das inseparáveis dimensões do ensino e da pesquisa, porque não via hierarquias entre elas. $\mathrm{O}$ que desejava era contextualizar melhor de onde veio essa preocupação com as medievalidades como objeto de investigação histórica e historiográfica. Nessa parte, aproveitei para tecer alguns contornos conceituais um pouco provisórios desse termo e como vinha utilizando-o no âmbito do LETHAM. Na segunda parte, dei diversos exemplos mais qualitativos e diretos para que poderíamos ver a medievalidades em movimento e discutir como e por que elas se correlacionavam com contextos políticos e ideológicos. O foco centrou-se nas medievalidades políticas representadas em vídeos, memes e notícias de jornais contemporâneos no atual contexto de recrudescimento de perspectivas conservadores, reacionárias, protofascistas e falogocêntricas.

Para legitimar esse campo de investigação já seria suficiente a contatação de que muitos de nossos alunos e alunas da graduação carregam noções de tempo e espaço medievais forjados pela cultura da mídia. Seja como for, considero importante ressaltar a necessidade de alargarmos ainda mais a noção de documento ou fonte histórica, algo que já fora iniciado pela Escola dos Annales, tão cara à historiografia brasileira, levando à sério a brincadeira, isto é, transformando a cibercultura e as mídias estáticas, dinâmicas e imersivas em objetos de investigação histórica e historiográfica, em diálogo permanente e renovado com a Educação e os Estudos de Gênero, entre outros campos interdisciplinares.

LETHAM: Ainda que de forma variável, é fato que os estudos medievais têm crescido no Brasil e ganbado espaço em vários programas de pós-graduação de universidades com uma relevante produção científica. No entanto, o senso comum acadêmico tem criticado muitos desses estudos, por terem um grande foco no mundo europeu e, por isso, não darem conta de realidades relacionadas ao contexto no Brasil. O que tem a dizer sobre essa afirmativa? E se a crítica tem um algum nivel de relevância, como fazer para solucionar esse problema?

MPL: É muito importante sinalizar que as universidades podem produzir alguma escala de senso comum. Embora isso não possa ser generalizado, pois a característica central da academia é ser um lugar de permanente questionamento das visões preconceituosas e estereotipadas sobre quaisquer temas, as culturas universitárias podem ser tão cúmplices quanto críticas da sociedade em que está situada, mesmo quando escolhe e acolhe outros tempos como objeto de estudo, como faz a História. Extrapolando a reflexão de Terry Eagleton sobre a ideia de cultura, quando aponta que "a cultura não está nem dissociada da sociedade nem totalmente integrada nesta" (EAGLETON, 2000, p. 19-20), posso dizer que a universidade é também uma espécie de encruzilhada de tradições, mas igualmente tem o propósito de produzir ensino, pesquisa e extensão que analisem e expliquem o mundo de maneira científica e autocrítica.

As dificuldades da academia em criar espaços simétricos e horizontais entre domínios, abordagens e dimensões, para usar as palavras de José D’Assunção de Barros (BARROS, 2012, p. 95), em parte têm a ver com a (in)compreensão mútua e as tensões simbólico-materiais e institucionais entre as áreas historiográficas. Em se tratando da História Medieval nos espaços acadêmicos, a resposta mais 
interessante a essas questões foi dada recentemente pelo professor doutor André Luis Pereira Miatello, da Universidade Federal de Minas Gerais. Eu a adoto aqui. Em 2017, ele diz: "Não precisamos carregar o fardo de sermos especialistas em um período ao qual ninguém dá valor: o valor não pertence ao período, mas à história. Se o nosso trabalho for bom para a historiografia, e me refiro às nossas publicações, não importa que seja sobre História Medieval: ele terá o reconhecimento que merece. Será preciso lembrar que Marc Bloch, Georges Duby e Jacques Le Goff são respeitados, não por serem medievalistas, mas por serem historiadores e difusores de uma nova história?”. (MIATELLO, 2017, p. 80-81)

Não podemos deixar de relacionar essa questão também ao campo de disputas políticas e formas de financiamento entre as Ciências em geral e as Ciências Humanas ou Sociais em particular. Em um contexto de negacionismos ideológicos, redução de recursos públicos para a produção de conhecimentos acadêmicos e crises socioeconômicas, esses fatores tendem a acirrar os tensionamentos no próprio campo da História. A solução é tornar mais simétricas e horizontais as relações entre áreas, campos e domínios, sem um "salve-se quem puder" acadêmico, sem priorizar uma ou outra área com recursos, apoios financeiros, renovação de quatros institucionais por meio de concursos etc. Pelo contrário, embora a disputa em espaços intelectuais e institucionais seja salutar, quando isso problematiza e desloca saberes institucionalizados, conservadores e reacionários, a hierarquização universal entre saberes historiográficos, baseados em dimensões geográficas ou escalas temporais mais legítimas do que outras, reproduz uma miopia epistemológica que não percebe as interseções entre os saberes, o senso de coletividade e a colaboração mútua. A campo dos Estudos Medievais não é ou não é mais somente um manancial de textos eurocêntricos e masculinos sobre a Europa. A Europa tem sido revisitada e reconectada a outros tempos e regiões não europeias. (SILVEIRA, 2019, p. 210-236) Novos-velhos sujeitos têm sido incluídos nas análises da medievalística, tais como os camponeses, marginalizados, mulheres, prostitutas, sodomitas etc. Documentos já batidos são revisitados a partir de novas abordagens teóricas e epistemológicas (Marxismo renovado, História Cultural, Nova História Política, Estudos Feministas, História Social das Mulheres, História das Masculinidades, Estudos Queers, entre outras). A História Medieval acompanha outros campos das Ciências Humanas, mas também tem algo a dizer e contribuir nesse processo de renovação permanente.

LETHAM: Atualmente, muitos setores conservadores têm empreendido esforços em produzir conteúdos que abarquem a História Medieval, sobretudo para legitimar uma visão conservadora da história. Com sua experiência de medievalista, como você vê esse fenômeno? Por que a Idade Média? É possivel superar essas posturas conservadoras?

MPL: Em grande medida, esse fenômeno não está isolado e não é exclusivo da História recente do Brasil. Em outras ocasiões históricas, o tempo foi abarcado de acordo com perspectivas ideológicas e posicionamentos políticos. No Brasil, os usos do passado sofreram um recrudescimento em função das crises ideológicas, político-partidárias, econômicas, jurídicas e multimidiáticas após o impeachment da presidenta Dilma Rousseff. A polarização política foi terreno fértil para os usos do passado. Cheguei a 
tecer algumas considerações sobre isso na palestra que ministrei para o Translatio Studii, já citada, quando discorri sobre os conceitos de neomedievalismo popular ou medievalidades políticas. Naquela ocasião, tentei definir alguns contornos do que tenho entendido por “(neo)medievalidades políticas”, inspirandome um pouco nos trabalhos Daniel Wollenberg (WOLLENBERG, 2018), embora ele não use propriamente o termo. Portanto, as (neo)medievalidades políticas seriam aquelas ideias, valores, crenças, discursos, representações, mas também atitudes, práticas e performances que são veiculadas pelas mídias e redes sociais, usando a escrita, a voz ou a imagem estática ou em movimento para expressar posicionamentos político-ideológicos de pessoas, grupos, classes, segmentos de classes e instituições, e que precisam ser correlacionados metodologicamente a diversos marcadores sociais e históricos, tais como os aspectos culturais, religiosos, étnico-raciais, às "racializações", os aspectos econômicomateriais, como também os marcadores políticos, ideológicos e baseados eventual ou marcadamente no gênero.

Basta citar o mesmo exemplo que dei na palestra e ligado ao caso que ocorreu no SESC de Pompeia quando Judith Butler veio ao Brasil para lançar um livro que não tinha diretamente relação com as questões de gênero, chamado Caminhos Divergentes: Judaicidade e Crítica do Sionismo, em que tratava do conflito Israel-Palestina e para participar de um Colóquio, que, se eu não me engano, chamava-se Os Fins da Democracia. Isso ocorreu em 2017. Embora a autora seja conhecida na academia por uma outra obra, chamada Problemas de gênero: feminismo e subversão da identidade (BUTLER, 2003), tardiamente publicada e lida no Brasil, a manifestação que ocorreu no SESC em São Paulo reuniu pessoas contra e a favor de Judith Butler. Além disso, houve a queima de uma boneca carregada em estandarte, representando Butler, com o rosto dela; era uma boneca vestida de preto com chapéu de bruxa e sutiã rosa, que reproduz a estética dos filmes americanos e do Halloween. As imagens que ficaram registradas pela Imprensa, para mim, constituem uma crónica dessa guerra de narrativas que não ficam só no plano virtual e, dependendo do estímulo contextual de disputas políticas, geram ações, legitimando-as, perpetuando-as. Butler foi associada diretamente como uma espécie de promotora da ideologia de gênero, tanto apregoado acriticamente por movimentos políticos reacionários como o Escola Sem Partido e o MBL. Só para ilustrar, cheguei a pegar um vídeo que foi divulgado pelo The Intercept Brasil que fez uma coisa interessante ao colocar as imagens e discursos dos dois lados, contra e a favor (GONÇALVES, 2017). Quando se separa e se serializa os discursos, dá para perceber claramente as posições políticas e a contraposição entre ciência e senso comum, entre estudos de gênero e posturas ideológicas essencialistas.

De um lado, por exemplo, havia diversos grupos orientados para negar o que chamavam de ideologia de gênero visto como um projeto das esquerdas, vistas como grupos degenerados sexualmente, que atuariam contra a família. Obviamente, a concepção de família é bem específica, apesar de ser colocada de uma forma universal. Tal família é vista como família nuclear, heterossexual e heteronormativa, ou heterocêntrica, formada por um homem e uma mulher, cujo papel seria educar seus filhos de forma binária, seguindo o que acreditavam ser o biológico. Ou seja, uma família patriarcal, 
conjugal, monogâmica e heterossexual e branca. É claro que isso também se tratava de uma pauta liberal em que a educação dos filhos é responsabilidade da família heterossexual contra o que consideravam incentivos à zoofilia, pedofilia e à homossexualidade, isso colocado em associação direta. É um discurso essencialista, conservador, antidemocrático e anti-intelectualista.

De outro lado, ainda no vídeo divulgado pelo The Intercept Brasil, temos as manifestações que tentavam mostrar o gênero como parte das pautas democráticas de luta ou combate às discriminações e desigualdades sociais de maiorias exploradas e minorias numerosas discriminadas. Não dá para separar esses casos de medievalidades políticas do contexto neoliberal e capitalista e do recrudescimento de pautas conservadoras, especialmente da movimentação encabeçada pela Escola Sem Partido e do MBL, especialmente as crenças em 5 dos seus pilares: o de que o conhecimento tem que ser absolutamente neutro e imparcial (o que não existe em lugar nenhum, o que não quer dizer que não se tenha que ter posturas científicas e éticas); a ideia de que os professores e professoras são doutrinadores(as) inveterados de esquerda (o que está longe da realidade, porque o desafio hoje é justamente enfrentar a dificuldade de influenciar e concorrer com as outras mídias e instituições, como a própria família e a Igreja, para persuadir nossos alunos para o pensamento crítico); há a ideia de que a responsabilidade da educação das crianças é exclusiva dos pais (reproduzindo o princípio, "Meus filhos, minhas regras"). Imagine vocês se tivermos pais e mães irresponsáveis e violentos? Sustentando a Escola Sem Partido, há ainda a ideia de que é preciso censurar e controlar a produção de conhecimento, o que é anticonstitucional, sem dúvida, e, por fim, há a ideia de que não se pode difundir a ideologia de gênero nas escolas.

Nas posturas "anti-butler-ideologia de gênero", há uma espécie de prolongamento estilizado e político da caça e punição na fogueira das bruxas, não para os séculos XVI e XVII, mas para um "medievo-moderno" visto como algo aceitável para combater um inimigo simbólica e efetivamente. O símbolo também é poderoso. Mas, vejam, as medievalidades políticas não são exclusividades de posturas conservadoras, reacionárias ou protofascistas. A jornalista, responsável pelo texto do The Intercept Brasil, embora mais crítica e movida por valores democráticos que inegavelmente, claro, valorizam a diversidade identitária, também reproduz um estereótipo inverso, anacrônico e explícito, aproximando um medievo genérico, associado à intolerância, ignorância e autoritarismo, com o evento do SESC Pompeia. E deixa clara uma aproximação arbitrária entre presente e passado. Diz ela na reportagem: “APROVEITANDO A PASSAGEM da feminista, lésbica, judia, ativista LGBT e teórica queer Judith Butler pelo Brasil, um grupo de direita se inspirou livremente na Idade Média para promover uma caça às bruxas em pleno 2017, fazendo uma queima simbólica da filósofa em um protesto em frente ao Sesc Pompeia, nesta terça (7), em São Paulo. Empunhando crucifixos, manifestantes atearam fogo em uma boneca vestida de bruxa com o rosto de Butler aos gritos de 'queimem a bruxa!'” (GONÇALVES, 2017, respectivamente, grifo da autora e grifo nosso)

Em síntese, não dá para deixar de associar a politização das medievalidades à politização do tempo como um todo, como diria Rodrigo Turin, numa entrevista recente, intitulada "Tudo ao mesmo tempo: pandemia nos confinou a diferentes dimensões temporais" (SAYURI, 2020). E, da mesma forma, 
não consigo deixar de identificar uma politização genderizada do tempo e das medievalidades. É importante não deixar esse aspecto de lado, porque parece que os elementos analisados pela História Pública e pela História Global afetam as concepções de Historiografia e as concepções de tempo no senso comum midiático. Há tessituras dos tempos, articuladas e desarticuladas, sem um eixo orientador, algo sentido e vivido como algo acelerado e mediatizando a mutação do conhecimento, da sociedade, das tecnologias e das relações de poder. Essa aparente fluidez, flexibilidade, dispersão e dinâmica da produção de imagens, memes, gifs etc. no âmbito da cultura da mídia e da cibercultura afetam a forma de se viver a política, as concepções de tempo, temporalidades, sociedades etc. Isso tem a ver não somente como fazemos reflexões formais e informais sobre o passado e o passado distantes, e a maneira como isso é consumido no cotidiano, nas escolas e nas universidades: um passado branco, ocidental, de elite, aristocrático e masculino, patriarcal ou androcêntrico. Procura-se no passado algo que sirva para legitimar ou deslegitimar o presente. E o Medievo, como ocorre com outros tempos, acaba se tornandose um tema inesgotável para a busca dessas conexões. Essa atitude é apropriada por diversos grupos.

Não dá para desvincular as medievalidades políticas das lógicas capitalista, neoliberal, nem da continuidade, adaptação, ampliação e articulação do conservadorismo (no sentido de conservar um passado idealizado) ou reacionário (com posturas hostis à democracia) que tem expressão global e seu impacto no Brasil, mas esse processo de medievalidades politizadas é uma resposta à crise e aos movimentos sociais (movimentos negros, feministas, LGBTQI+, MST, entre outros), que também disputam espaço em busca de direitos, de acolhimento e participação públicas. Discutir como e por que as questões identitárias foram incorporados pelos grupos de direita é algo fundamental, entretanto, isso não pode ser confundido com a desarticulação identitarista. É uma reação aos movimentos identitários, usando as próprias identidades com sinais trocados. Os mundos medieval, europeu e ocidental acabam sendo uma referência que deveria se repetir para legitimar o controle, regulação ou desregulação dos direitos conquistados por esses grupos discriminados.

Mas sem sombra de dúvidas as neomedievalidades políticas têm algo a ver com o complexo processo intensificação das interconectividades das redes sociais que criam, reproduzem e alteram os regimes de verdade por meio da mistificação ou mitologização da história. A interação mediada por computadores, como diria Alex Primo (2007), e a hipertextualidade (que cria uma arquitetura labiríntica de informações, rompendo com a escrita e o conhecimento lineares), assim como os conteúdos multimidiáticos (sons, imagens e textos), a ampla disponibilidade e o baixo custo desses conteúdos, todos esses elementos têm contribuído para implodir a ideia de polo emissor de conhecimento. Sem falar que esses sites e memes servem também para ganhar dinheiro com venda de camisas etc. Isso tem impactado também medievalidades, tornando-as aparentemente descontínuas e dispersas, mas, se olharmos mais de perto, é possível perceber a conexão e articulação genérica com seus contextos de produção e apropriação históricas. Qualquer um pode produzir medievalidades políticas, mas o fazem dentro de uma historicidade e contextos políticos e socais determináveis etc. 
Mas a gente também não pode desvincular a cultura da mídia e a cibercultura das estratégias didático-pedagógicos, sobretudo se formos medievalistas e nos dedicamos a problematizar os aspectos políticos das medievalidades, especialmente criando ou rompendo discriminações, desigualdades e hierarquias. Estudando as medievalidades em rede, em movimento, é uma forma de se pensar como as pessoas anônimas ou não se posicionam, legitimam, contestam e resistem às ideologias e à vida social. Podem ajudar a manter, mas também podem alterar ao status quo. Essas medievalidades fazem parte de um processo mais amplo em que há uma relativa implosão do binarismo entre educação formal e informal, educação referencial ou muitireferenical vinculada pela internet; entre um currículo formal ou informal multireferencial. Podemos trazer o informal para atividades de educação formal, não quantitativista, não conteudista. A questão é que essa multireferencialidade é adotada politicamente por grupos e subgrupos em rede sem pontas que têm interesses e disputam lugares dentro e fora do Estado. Essa multireferencialidade, embora gere empolgação, sendo importante, não é neutra, e a educação histórica por meio das redes sociais pode gerar tanto posturas e conhecimentos críticos como acríticos.

Por isso, segundo David Marshall (MARSHALL, 2007), o estudo do medievalismo da cultura popular pode também melhorar a preparação dos medievalistas para ensinar seus temas, por mais estranho que isso parece, pois ao explorá-lo pode-se discutir as visões que os estudantes têm sobre os temas, especialmente porque muitos deles conhecem o medievo por meio da mídia popular, das medievalidades, como vídeo-games, a fantasia da cultura gótica, contos infantis, romances, filmes e jogos eletrônicos, mas também memes (MARSHALL, 2007, p. 9). Quanto mais fazermos isso de forma permanentemente crítica, precisa e científica, tanto melhor para a educação nos ensinos fundamental, médio e superior. Claro, precisamos fazê-lo nas doses e dimensões adequadas aos projetos políticos pedagógicos, à maturidade dos alunos e alunas etc., mas sempre reforçando as inseparáveis áreas da atuação do ensino, pesquisa e extensão, dentro ou fora das universidades.

LETHAM: A temática das epidemias na Idade Média tem sido revisitada numerosas vezes, sobretudo para tentar entender o contexto atual de pandemia. Se, por um lado, isso familiariza a sociedade com outros periodos da história que passaram por esse problema, por outro, ajuda a reforçar um estereótipo da Idade Média como um perído que predominava a peste, doenças, a chamada "Idade das Trevas". O que teria para dizer sobre isso?

MPL: Como apontei anteriormente, há usos ideológicos do passado, sem que isso seja claramente percebido como tal. Como já é sabido entre os especialistas nas mudanças ocorridas no século XIV, é inegável que houve crises sociais e mortes decorrentes da difusão de diversas epidemias com impactos diferentes em cada localidade. Amenizando ou não o conceito de crise, em prol de termos mais domesticados, como o de transformação, há controvérsias que giram em torno das motivações e conexões das epidemias com outros marcadores sociais, históricos e geográficos. A medievalística contemporânea tem identificado como as populações afetadas por elas lidaram de diferentes formas, reforçando inclusive pogroms empreendidos por grupos sociais e autoridades europeias contra judeus, mulheres e outros setores marginalizados. Do ponto de vista do senso comum, dificilmente, se vê a 
questão como momentos específicos e contextualizados no Medievo. É comum inflar a Idade Média de uma conotação temporal marcada não somente pela arbitrariedade dos senhores feudais, pelo poder incontornável da Igreja, da pobreza, mas também pela difusão das pestes, doenças e epidemias. O que reforça o estereótipo de que o Medievo é a antítese absoluta da modernidade ou da contemporaneidade. Tudo isso reforça conexões ou desconexões muito artificiais com o Medievo, como se as características, alcances e motivações das epidemias fossem absolutamente iguais ou antitéticas, tornando-os (in)comparáveis.

LETHAM: Uma das dificuldades de muitos alunos, e até mesmo de professores, no ensino básico, é aproximar o ensino de história em sala de aula com outras vivências e práticas do alunado. Se isso já é um problema para falar de outros periodos, parece que, quando o assunto é Idade Média e Antiguidade Clássica, a dificuldade fica muito mais evidente. Levando em conta que já foi professor do ensino básico, como "trazer a Idade Média" para a sala de aula, despertando interesse do aluno pela temática, de tal modo que ele possa refletir sobre o medievo em suas práticas diárias? Existe essa possibilidade?

MPL: De fato, fui professor do ensino fundamental por 10 anos entre 2001 e 2011 na Secretaria Municipal de Educação do Rio de Janeiro e na Secretaria Municipal Angras dos Reis. O medievo já fazia parte das minhas expectativas e práticas profissionais. Sempre que podia e quando o currículo escolar assim o exigia, as temáticas, abordagens e documentos produzidos na Idade Média eram incluídos na vida escolar. Desde a graduação, questionava uma educação tradicional, conteudista, apassivadora de sujeitos, uma Educação Bancária, como diria Paulo Freire (FREIRE, 1970, p. 70; BRIGHENTE, 2016, p. 155-177). Problematizava uma educação que não valorizava a trajetória dos alunos e alunas, e reproduzia a dicotomia entre estudantes e professores em que o docente era visto como aquele que depositava ativamente o conhecimento nos discentes, fazendo tábua rasa dos alunos e alunas. Isso incomodava-me permanentemente. É claro, meu intuito não era reproduzir a pauta de conteúdos acadêmicos de História Medieval para aos alunos e alunas do ensino fundamental, porém minha formação acadêmica já vislumbrava a clareza de que os aspectos conceituais, metodológicos e historiográficos deveriam ser filtrados, dosados e adaptados para as realidades discentes de cada escola, turma e idade. Os filtros e adaptações eram vistos por mim como um caminho que mesclava a simplificação e a complexificação dos conteúdos conceituais, procedimentais e atitudinais.

Essa situação implicava em conhecer a formação e realidades sociais dos(as) discentes, contextualizando-as às informações pessoais, familiares, escolares, sem deixar de conectá-los aos problemas do bairro, município ou país, ou mesmo aos que chegavam à sala de aula sobre assuntos internacionais. Mesmo em se tratando dos primeiros anos do ensino fundamental, justamente quando os temas ditos medievais estavam mais presentes como assunto central, lembro-me que tentava não subestimar ou superestimar os alunos e alunas, ficando atento aos conhecimentos prévios e construindo outros novos em sala. O que estava claro à época era que a Idade Média poderia ser um bom pretexto para ensinar noções de tempo, espaço, sociedade, cultura, religião, instituição, poder, economia, relações 
de gênero, identidade, alteridade, tolerância, intolerância, memória, entre outros aspectos. É claro que a adesão dos discentes do ensino fundamental exigia lidar com os problemas da aproximação emotiva, criativa e racional com determinados temas. O desafio do conhecimento histórico estava no fazer sentido para os(as) discentes, sem que isso implicasse em abdicar das características científicas do campo.

Em parte, isso ocorre no ensino de História na graduação, embora seja em uma dimensão e escalas distintas, visto que os alunos e alunas dos ensinos fundamental e médio não estão sendo educados e instruídos para serem historiadores e historiadoras. O caminho de combinar o Ensino de História e um Educação Inatual, como diria o medievalista Nilton Mullet Pereira, requer romper e deslocar simultaneamente as perspectivas passadistas, que sacralizam os tempos remotos, colocando-os num pedestal, ou visões presentistas, que procuram submeter o passado às demandas do que vigora no aqui e agora. O maior desafio de alunos e professores(as) não é captar e assimilar um número incontável de datas, sujeitos, factualidades, eventos, localidades ou temporalidades. Pelo contrário, na lógica da seleção criativa e consciente, nas dobras das relações entre História, História Medieval e Ensino de História, o que é fundamental é aprender diariamente a situar-se diante do mundo, compreendendo-o, para atuar sobre ele. O ensino de História Medieval, talvez, possa contribuir com alguns tijolos na formação de alunos e alunas críticos e colaborativos.

LETHAM: Quando pensamos em epidemias ao longo da História da bumanidade, acionamos logo a Peste Bubônica do século XIV como o primeiro exemplo a ser citado (se não um dos primeiros). Percebemos, inclusive, um fluxo de professores e professoras que buscam, através do ensino das epidemias, informar e conscientizar os(as) estudantes do ensino básico. Quais as principais comparações que podemos traçar entre estes dois processos? De que forma a compreensão e a comparação entre as epidemias podem ser usadas de forma mais eficiente no contexto em que vivemos hoje?

MPL: Não sou especialista no estudo das epidemias medievais. Há livros, artigos e podcasts bem mais completos nessa discussão que podem ser consultados. (BASTOS, 2009; Cf. FÉO; MAGELA, 2020) Contudo, posso responder essas questões fazendo algumas reflexões metodológicas. Em primeiro lugar, como estamos entendendo comparação para o campo da História? Há um programa de pós-graduação inteiramente dedicado ao tema na UFRJ, chamado Programa de Pós-Graduação em História Comparada (PPGHC), ${ }^{3}$ e uma revista acadêmica especializada, ligado a esse programa, intitulada Revista de História Comparada. ${ }^{4} \mathrm{Em}$ ambos os casos, vale a pena ler os artigos dedicados à comparação no medievo.

Segundo Jürgen Kocka, "comparar em História significa discutir dois ou mais fenômenos históricos sistematicamente a respeito de suas similaridades e diferenças de modo a se alcançar determinados objetivos intelectuais" (KOCKA, 2003, p. 39) Ainda segundo esse autor, a comparação tem alguns propósitos heurísticos, descritivos, analíticos e paradigmáticos. Ou seja, ela serviria para "identificar questões e problemas que se poderiam de outro modo perder, negligenciar ou apenas não inventar". Ela poderia "esclarecer os perfis de casos singulares, frequentemente de apenas um único

\footnotetext{
${ }^{3}$ Programa de Pós-Graduação em História Comparada PPGHC-UFRJ: https://ppghc.historia.ufrj.br/.

${ }^{4}$ Revista de História Comparada: https://revistas.ufrj.br/index.php/RevistaHistoriaComparada.
} 
caso, ao contrastá-lo com outros". Além disso, o exercício comparativo permitiria "levantar e responder questões de causa", isto é, pensar as razões explicativas de determinados fenômenos históricos ou historiográficos. E, por fim, numa relação de estranhamento e familiarização com o passado, ela "pode ter um efeito desprovincializante, liberador, abrindo perspectivas, com consequências para a atmosfera e estilo da profissão" KOCKA, 2003, p. 39-41).

É claro que aplicar todas essas funções metodológicas da comparação para a epidemias ultrapassaria meu propósito aqui. Todavia, mais interessante, seria pensar um roteiro heurístico, descritivo, analítico e paradigmático para a construção das aulas potenciais. Por exemplo, quando comparamos as epidemias do século XIV com as contemporâneas, sobretudo as do 2020, o caminho mais adequado não é nem aproximar demais ou distanciar excessivamente os dois fenômenos históricos. Em termos heurísticos, pode-se perguntar quais as similaridades entre o senso comum baseado em saberes religiosos ou morais sobre as formas de transmissão das doenças. Em termos descritivos, não é secundário estimular os(as) discentes a identificar os detalhes sobre os circuitos geográficos das transmissões, diferenciando a dinâmica euroasiática medieval e a escala global e internacional contemporânea. Em termos analíticos, constitui um esforço importante identificar as motivações sanitárias, sociais, políticas, econômicas, culturais, religiosas etc., diferenciando as razões que permitiram a recrudescimento ou o arrefecimento das epidemias. E em termos paradigmáticos, pode-se estimular os(as) discentes a pensar crítica e amplamente o fenômeno das epidemias para além das questões biológicas e sanitárias, conectando-as a diversos marcadores sociais e históricos. Talvez, sem usar esses termos da metodologia acadêmica nas aulas, mas sem deixar de incorporá-los como pressupostos pedagógicos, o fundamental é o esforço de superar a identificação absoluta, que aproxima tempos que são distintos, ou a relação de alteridade absoluta com o passado, que desloca e reduz os pontos de contato, aproximações e convergências.

LETHAM: Em tempos de crise, nos vemos muitas vezes desamparados e desacreditados. As Ciências têm sido o instrumento utilizado para garantirmos um futuro e tem sido a nossa arma para tentar combater o COVID-19. Como o uso da História, em geral, e da História Medieval, em particular, pode contribuir para enfrentarmos hoje os limites que a crise e pandemia nos impõem? Em que medida o conhecimento histórico pode ajudar a acalmar os ânimos, os receios, até mesmo dar esperança e/ ou combater como "protagonista" a COVID-19?

MPL: Trata-se de um trabalho hercúleo que não diz respeito somente ao papel da História na vida social e política contemporâneas. Não estou certo de que o papel dela seja terapêutico, paternal ou maternal da História nos seus sentidos tradicionais. Longe de querer ser irônico, é preciso salientar que há outras áreas de conhecimentos humanos e dos movimentos sociais que são muito mais promissores para lidar com anseios, receios e acalmar os ânimos. Em verdade, o campo da História pode servir exatamente para o inverso disso: produzir, manter e legitimar os conflitos e tensões sociais. Do ponto de vista político, isso pode submeter às demandas tradicionais, conservadoras, reacionárias e até protofascistas. Mas pode estar a serviço da democracia e do combate às desigualdades, preconceitos e discriminações 
sociais, em especial às formas de elitismos, racismos, LGBTfobias, machismos e antiintelectualismos. Do ponto de vista acadêmico, a História em geral e a História Medieval em particular não são ou não deveriam ser "mestras da vida", reproduzindo conteúdos morais e exemplos do passado para se impor no presente. Nem tampouco deve ser uma projeção acrítica e automática das expectativas atuais sobre o passado. Não tenho dúvida de que fazemos História no, a partir e para o presente sobre o que chamamos de passado. Isso nos impõe que não podemos ignorar as soluções dadas por homens e mulheres de outros períodos para pensarmos nossas próprias temporalidades, identificando as similaridades, aproximações, convergências, mas também as diferenças, afastamentos e divergências entre o passado e o presente.

Contudo, as dimensões emocionais ou subjetivas que nos aproximam dos indícios do passado mesclam-se à precisão e à objetividade historiográficas. Com senso de coletividade, os(as) historiadores(as) medievalistas podem usar as armas que estão à mão ou exercitar o que sabem fazer de melhor: (re)pensar criticamente o passado, sem ser cúmplice dele. Na conjuntura atual, além do que já fazemos nos campos do ensino, pesquisa e extensão, não vejo outro caminho a não ser a ocupação de espaços físicos e virtuais cada vez mais amplos. Isso inclui as circunscrições e dimensões sociais, culturais e institucionais do Estado, mas também as disputas de narrativas nas ciberculturas e nas culturas na mídia, tais como o You Tube, Instagram, Facebook, Twitter etc. Não considero importante que as disputas por espaços e narrativas devam gerar um protagonismo exclusivo da História Medieval, porque, longe disso, ele não deve apagar o senso de colaboração com outras Ciências Humanas. Embora outros grupos sociais estejam ou deveriam estar na linha de frente do combate ao COVID-19, como as secretarias de saúde, médicos, enfermeiros, o campo da História não está isolado do restante da sociedade e tem algo a dizer sobre o aqui e alhures. Sem cair em utilitarismos epistemológicos para legitimar os conhecimentos histórico e historiográfico, podemos dar nosso quinhão para desfazer equívocos, sensos comuns, simplificações e preconceitos sobre quaisquer tempos, incluindo o nosso e o medieval.

\section{REFERÊNCIAS}

BARROS, J. D’A. de. O projeto de pesquisa em História. Da escolha do tema ao quadro teórico. Petrópolis: Vozes, 2012.

BASCHET, J. Por que se interessar pela Europa medieval? In: BASCHET, J. A civilização feudal: do ano 1000 à colonização da América. São Paulo: Globo, 2006. p. 23-46

BASTOS, M. J. da M. O poder nos tempos da peste (Portugal - séculos XIV/XVI). Niterói: EDUFF, 2009.

BRIGHENTE, M. F.; MESQUITA, P. Paulo Freire: da denúncia da educação bancária ao anúncio de uma pedagogia libertadora. Pro-Posições, v. 27, n. 1 (79), p. 155-177, jan.-abr. 2016.

BUTLER, J. Problemas de gênero: feminismo e subversão de identidade. Rio de Janeiro: Civilização Brasileira, 2003. 
COSTA, M. R. N.; COSTA, R. F. Mulheres intelectuais na Idade Média. Entre a Medicina, a História, a Poesia, a Dramaturgia, a Filosofia, a Teologia e a Mísitica. Porto Alegre: Editora Fi, 2019.

EAgleton, T. A ideia de cultura. Lisboa: Temas e Debates - Actividades Editoriais, 2000.

FÉO, C. MAGELA, T. Epidemias na História - Episódio 1. Podcast com o professor doutor Mário Jorge da Motta Bastos (UFF) e Ricardo Augusto dos Santos (pesquisador da Casa Oswaldo Cruz). Disponível em: https://www.youtube.com/watch?v=30JL2MHQScM. Acessado em: 20 dez. 2020.

FRANCO JUNIOR, H. A Idade Média Nascimento do Ocidente. São Paulo: Brasiliense, 2001.

FREIRE, P. Pedagogia do oprimido. Rio de Janeiro: Paz e Terra, 1970.

GONÇALVES, J. “Queimem a bruxa!” Visita de Judith Butler provoca manifestações nas ruas de São Paulo. The Intercept Brasil, 7 nov. 2017, 19h14. Disponível em: https: / theintercept.com/2017/11/07/judith-butler-bruxa-manifestacoes-sao-paulo-ideologiagenero/. Acessado em 04 dez. 2020.

KOCKA, J. Comparison and beyond. History and Theory, n. 42, p. 39-44, 2003.

LIMA, M. P. Gênero, Ensino de História e Medievalidades: (des)conexões com o passado. Signum Revista da Abrem, v. 20, p. 148-193, 2019.

LIMA, M. P. Poderes, corpos e performances de gênero: feminilidades e masculinidades no Tratado en defensa de virtuosas mujeres de Diego de Valera. Anos 90, Porto Alegre, v. 27, p. 1-20, 2020.

LIMA, M. P..; ALVARO, B. G. Documentação diplomática da diocese de Sigüenza entre 1124 e 1151. Salvador: EDUFBA, 2019.

LIMA, M. P.; MEDICCI, A. P. Políticas em História: instituições, poderes e historiografia. Salvador: EDUFBA, 2019.

LIMA, M. P.; SILVA, V. F. da. O poder da fala e a imposição do silêncio: exercício da religiosidade laica e restrições de gênero no século XIII. In: SILVA, S.; SILVA, A, C. L. F.; SILVA, L. R. Atas do Ciclo A Tradição Monástica e o Franciscanismo, 2002, Rio de Janeiro, 2002.

MACEDO, J. R. Entrevista com José Rivair Macedo: a consolidação do campo de História da África Antiga no Brasil. Romanitas: Revista de Estudos Grecolatinos, n. 10, p. 11-25, 2017.

MACEDO, J. R. Introdução. Cinema e Idade Média: perspectivas de abordagem. In: MACEDO, J. R.; MONGELLI, L. M. (org.). A Idade Media no cinema. São Paulo: Ateliê Editorial, 2009.

MARSHALL, D. M. Mass Market Medieval: Essays on the Middle Ages in Popular Culture. North Caroline: McFarland \& Company, 2007.

MIATELlo, A. L. P. A História Medieval na graduação em História: da pesquisa à Docência, Revista Chilena de Estudios Medievales, n. 11, p. 68-90, 2017.

PRIMO, A. Interação mediada por computador: comunicação, cibercultura, cognição. Porto Alegre: Sulina, 2007.

RIVERA GARRETAS, M.-M. La diferencia sexual en la historia. València: Publicacions de la Universitat de València, 2005.

SAYURI, J. Tudo ao mesmo tempo: pandemia nos confinou a diferentes dimensões temporais. TAB. Entrevista realizada com Rodrigo Turin, 12/08/2020). Disponível em: 
https://tab.uol.com.br/noticias/redacao/2020/08/12/tudo-ao-mesmo-tempo-pandemia-nos-confinou-adiferentes-dimensoes-temporais.htm. Acessado em: 21 dez. 2020.

SILVA, A. C. L. F. Reflexões sobre o uso da categoria gênero nos estudos de História Medieval no Brasil. (1990-2003). Caderno Espaço Feminino, v. 11, n. 14, p. 87-107, jan.-jul. 2004.

SILVA, M. C. da. A fabricação da Idade Média. In: SILVA, M. C. da.. História Medieval. São Paulo: Contexto, 2019.

SILVEIRA, A. D. da. História Global da Idade Média: Estudos e propostas epistemológicas. Roda da Fortuna. Revista Eletrônica sobre Antiguidade e Medievo, v. 8, n. 2, p. 210-236, 2019.

WOLLENBERG, D. Medieval Imagery in Today's Politics. Leeds: Arc Humanities Press, 2018. 